\title{
Statistical analysis of SCI Ppers in Higher Universities at new Stage
}

\author{
Wang Yinhong, Wan Li, Lei Xinhua, Zhang Fangfang \\ Department of Science and Technology, China University of Geosciences, Xueyuan \\ Road, Beijing 100083, China
}

\begin{abstract}
At present, SCI is not only an important retrieval tool in the world, but also one significant index used to evaluate academic level of a country, a university or research personnel, so more and more higher universities pay much attention to the quality and quantity of SCI papers. Authors have mainly analyzed the current condition of SCI papers published in higher universities of our country and found some main problems about it, such as low quantity and poor quality, a low citation rate, rare original fruits, and unequally distributed subjects. Based on the present situation and problems above, authors suggest that higher universities should propagandize the considerable function of scientific and technical papers with high quality, build superior research environment, enhance international cooperation and communication in science and technology, strengthen application of information network system, and deepen reform of the management system for science and technology, so as to promote the development of academic research in higher universities and to enhance the academic level and popularity.
\end{abstract}

Key words: higher universities; SCI papers; quantity; quality

\section{Introduction}

Science Citation Index (SCI) published by the American Science Information Institute is one extremely influential tool to quantitatively evaluate the performance of scientific research. SCI has included high quality research papers in various disciplines, which can represent world level of each field [1]. Therefore, based on the citation rate of papers and whether being included by SCI, it is comparatively objective and fair to use the method of scientific metrology to appraise international academic position and research capacity of higher universities, scientific research institutes or personnel, and the development trend of different disciplines and so forth.

The output of high level scientific papers can signify technological power of higher universities, so the number of SCI papers becomes a significant index to evaluate a university's international influence on science and technology. For SCI paper is a literal expression of natural science achievements, the quality and quantity of that is not only important to estimate academic level of colleges and researchers' ability of doing scientific study, but also imperative in various aspects such as title promotion, academic degree evaluation, program assessment and reward selection [2]. In order to improve science and technology productivity of our country quickly, it is necessary to know how to tremendously publish high- 
quality SCI papers, how to promote the scientific level of higher universities and how to realize the all-round development of scientific research work. According to the output of SCI papers and existing problems, authors have made an analysis and put forward some countermeasures of publishing more SCI papers, so as to promote the rapid development of scientific and technological industry of higher universities.

\section{The Existing Problems Of Sci Pa- pers In Higher Universities}

According to the statistical results of SCI papers published by China's researchers, both of the international scientific papers and domestic technological papers from higher universities account for larger percent, so promoting publishing high level scientific papers is the key. Overall, along with the development of science and technology, China's soft and hard conditions of it in higher universities have been certainly improved, meanwhile research funding has increased. Therefore, colleges pay more attention to improving both the quantity and quality of scientific papers at the same time. The improvement mainly displays in that the number of scientific papers rose rapidly, that some highly influential technical papers published, and that scientific papers in high impact journals have a conspicuous growth $[3,4]$. All of these show that the influence of SCI papers has enhanced, which represent the generally increasing level of scientific research of universities. However, comparing with foreign firstclass universities, the number of scientific research achievements in higher universities of our country is less, coupled with the lower quality and fewer quantity of SCI papers. Therefore, different universities in our country have different levels of science and technology, which means that there is still a certain gap to reach the advanced world standard.

Currently, the more high quality papers published by scientific research units, the higher academic influence they will have. Although the scientific research achievements are not small in quantity, the high quality of them is not enough. There are several major problems in publishing SCI papers in higher universities.

\subsection{The quantity and quality of SCI papers is not high}

In recent decades, along with the rapid development of science and technology, the research level of each Chinese university has a considerable improvement. At present, universities more actively take part in the national and local economic construction; and the scientific research funding could come from more channels. The national government has given considerable support to universities for the development of scientific research, and increased capital investment to research platform and group, which brings dramatic space for the development of higher universities. In addition, because the quality and quantity of SCI papers is a proper standard by which to judge the scientific research ability of a unit, SCI paper quickly becomes the goal that the Chinese science and technology and education constantly pursue $[5,6]$. Although the number of papers published by higher universities has been increasing greatly, the output of SCI papers is still low. There still exists a large gap compared with world class universities. What's more, since the number of scientific research project, research funding, and the amount of published SCI papers are important indexes in evaluation system of teachers' scientific research, it causes a fierce competition among researchers and scientific research blundering phenomenon. Some scientific research personnel prefer to pursue the quantity of papers, 
and neglect the improvement of the quality of them, so that the thesis in SCI is not high in quality.

The reason that the quantity and quality of SCI papers are not high can be elucidated from several respects as follows [7, 8]. First, for some scientific research personnel or teachers, the center of their work is not on the scientific research work; for some others, they aim at obtaining a plenty of research projects rather than trying to do them well; there are also others who do not have enough energy to concentrate on the scientific research work because of the long time teaching. Second, along with the expansion of post graduate in our country, the number of postgraduates enrolled increases year by year, causing both positive effect and negative effect. For example, the expansion makes some not excellent students become graduate students, which increases the difficulty of management and makes the task of each tutor aggravated. It inevitably adds great burden to some scientific research mentors in research work. Third, some advisers' scientific research projects are completed by postgraduates while they themselves pay little attention to it, so it is impossible to guarantee the quality of scientific research. Fourth, with the purpose of title appraise and applying for research projects, some teachers intend to increase the amount of papers by publishing several similar papers derived from a same content. Fifth, technically speaking, it requires English expressing ability and high quality of experimental data for writing foreign SCI papers. However, currently, many teachers' specialty English level needs to be improved, and their scientific research ability in all fields needs to be strengthened. Sixth, the nominal phenomenon seriously exists in science and technology papers. With multi-subjects crossover and penetrating, the quantity of co-authored papers increases. But, in some co- authored papers, due to the influence of several factors, there exists impractical and fraudulent nominal phenomenon. For example, some people hurriedly pursue the quantity of papers through using unfair means to be nominal, while others make someone nominal for some special relationship or repaying relatives and friends. This phenomenon occurs constantly in higher universities. The unfair competition not only violates the copyright and affects journal's credibility also reduces other scientific research personnel's enthusiasm and passion. What's more, it has lots of negative effects on the evaluation of teachers' professional titles. Therefore, the nominal phenomenon has greatly hampered the development of scientific research career. All of these reasons are restricting the improvement of the quality and quantity of the papers published.

\subsection{The SCI papers have lower aver- age citations}

Each scientific research activity must be based on learning and referring predecessors' achievements, and done by learning others' experience. A SCI paper with high academic value must cause considerable attention of peers and citations, so the cited number of scientific and technical papers is an eventual standard to measure the quality of paper-with the higher quality, it will be more cited and have more influence.

According to the 2011 Statistical Report of Institute of Scientific and Technical Information of China [2], SCI papers published by our scientific researchers are totally cited 5.1914 million times from 2001 to November 1, 2011, ranking seventh in the world, which climbs one place over the last year based on accumulative cited times to see the current cited situation of our country's SCI papers. From average cited number to see the current cited situation of our 
country's SCI papers, it is estimated that each paper is averagely cited 6.21 times, which increases 5.8 percent over the last year. In contrast, the world average cited times is 10.71, ascending 1.3 percent over the last year. Therefore, we can realize that our country's average cited times are improving relatively fast, but there is still a large gap compared with the world's. From 2001 to 2011, there were fifteen countries whose total scientific papers published are more than 20 thousand pieces. According to the average cited number of each paper, our country ranks thirteenth. It shows that there are 10 countries where the average cited times are over 10 times, and only 6.21 times in our country The United States has the prominent advantage with 16 cited times of each paper, and the quantities of papers published in USA and that of the second county are not in the same amount class. We have a long way to go in two regards that is the accumulative cited times and average cited times compared with the advanced world levels. Higher universities are the dominant output unit of our county, so it can be indirectly reflected that SCI papers from universities is also cited less and is low in quality and influence.

International usually use "impact factor" to measure the academic level of scitech journals. The bigger figure means the higher academic level of the journal [9]. The impact factor can reflect how many times the papers published in this journal being cited by peers. In general, papers, in journals with higher impact factor, they will be more possible to be cited and the quality is higher. Each subject's top journals are ones that the impact factor is the highest in that field. The impact factor of some international authoritative journal of science and technology can reach from 20 to 30 . In contrast, Chinese impact factor is still low. In addition to individual journal which can reach 4 , most are only one or even less than 1[3]. According to the statistics in 2010, the average "impact factor" of Chinese science and technology journals is 0.463 , and the average citation number of them is 971. Although the quality and impact of Chinese journal of science and technology has apparently increased than 2001 , the number of citation of articles included in SCI is very low, and some even not being cited. It partly reflects that the scientific research's level is comparatively low. It also reflects the defect of current scientific research system in higher universities.

However, the original achievements of higher universities are less. Analysis shows that SCI papers from original scientific research achievements have powerful influence, and can be widely cited. However, this kind of achievements is rare in universities. There are some unfavorable factors that deter scientific and technical personnel to make full use of their scientific research innovation ability, which leads to less original achievements, such as unreasonable disposition of resources, shortage of research funds or waste, scientific research platform like key laboratory used poorly.

The disciplines of SCI papers are not equally distributed. According to SCI database statistics, during the last decade, the disciplines of SCI papers mainly involve chemistry, materials science, physics, computer, mathematics, biology and geology. Due to the different degree of study of different disciplines, the number of papers published in each field varies greatly. Some disciplines can easily produce papers, while others can not. Therefore, relevant researchers are more apt to write papers about fields that have high degree of study, while the papers about the less focused fields become less and less. 


\section{Some Countermeasures On Promot- ing Publishing Sci Papers}

SCI is an international evaluation index to evaluate natural science foundation research achievements in an objective, quantitative and operational way, and it plays an important role in measuring scientific strength of each institution and academic level. Because of papers published in domestic journals affected by different kinds of factors, it is generally thought that papers which published in foreign journals included by SCI can reflect the academic level of scientists. So whether papers can be published in SCI journals and how high the impact factor of the journals are the crucial indexes to evaluate the academic level. Publishing SCI papers is an efficient way to forcefully improve the scientific level of universities, but not a final goal. The purpose of encouraging teachers to positively publish SCI papers is to make teachers produce high level scientific achievements, instead of just generally completing the research project. In the scientific activities, teachers should make great efforts to pursue doing better and more successfully; and only in this way that universities can promote the overall scientific level, as well as narrowing the gap with other colleges and first-class scientific research institutions. Based on these issues existing in universities now, there are some countermeasures are put forward.

\subsection{Build excellent scientific research environment}

To be creative means that we should do independent thinking, dare to doubt, have rich imagination, grasp the key point, broaden thinking and improve efficiency. Only scientific and technological personnel with creative thinking can pose new questions, make new discoveries and technology innovation, as well as put forward some valuable research topics
[10]. To improve the creative thinking of scientific and technological personnel needs good scientific research environment, so it is a key to create a positive and fair atmosphere of academic exchange, and to advocate academic moral norm of seeking truth from facts. It can help universities to introduce and condense talents, effectively integrate the excellent talents, and arouse the innovational ability of scientific and technological personnel, so that scientific research personnel can have opportunities to improve the quality and quantity of papers through reasonable ways. This paper will explain how to create superior research environment from the following three aspects.

First of all, the rational allocation of resources is an important means to create superior research environment. Dependent on their own advantages on science and technology, higher institutes should set up technology innovation base, reasonably plan exiting resources, invest necessary research funds, improve the fundamental conditions, construct the open research platform, and finally promote intercross among different disciplines.

Second, it is worthwhile to grasp construction of key laboratories. Universities must regularly increase investment to the key laboratories, improve laboratory technicians overall qualities and the level and quality of services of laboratories, so they can work better for scientific and technological personnel. Besides, in order to create a kind of cooperative and communicative atmosphere, universities are supposed to implement open policy in the key laboratories [11]. As a result, such a perfect scientific environment will be created and excellent scientific research team will be stable, and eventually high quality and level of research achievements will be achieved.

Finally, if we want to build excellent scientific research environment, certain 
scientific research funds is needed. Certainly, the multi-channel funds of scientific research can inject vigor to construct scientific research environment. Scientific research funds are usually gained from scientific research projects, especially from significant national ones, which not only have great significance to technology innovation of universities, but also offer excellent environment for improving talents' innovation consciousness and ability, as well as stimulate the innovation vigor of scientific research personnel.

Therefore, universities must establish the mindset that we should respect labor, respect knowledge, respect laborers, respect creation, so as to create a better environment for scientific talents to exploit their creative thinking to the full.

\subsection{Strengthen international coopertion in science and technology}

First, create scientific research team. In terms of the citations of each paper and impact factor of journals, it is analyzed that the achievements obtained from scientific research activities are better in form of "scientific research team" than in any other forms, in the current scientific papers included by SCI from universities. Actually, there are enormous amount of papers published in high quality. With the guidance of academic leader in a scientific team, every member works positively and initiatively, which can make scientific research activities done efficiently.

For higher universities, it is imperative to offer opportunities for scientific research personnel to make communication and cooperation with international first-class universities and famous research institutions, to strengthen academic exchanges and interaction between researchers of universities and respectable person at home and aboard, such as different forms of academic report or international academic conference, and to create a variety of research groups [12]. Afterwards, we can make full use of foreign advanced equipment and learn advanced scientific thoughts and methods, which can widen our sight and stimulate thinking, so as to raise the scientific research level of universities, to improve the ability of independent innovation, and to further improve the quality of papers.

Second, strengthen international coauthored paper published. In the process of scientific research, domestic and foreign researchers who have a common interest and scientific issues do research work through mutual coordination and intersection, and then obtain achievements. Based on this kind of international cooperation relationship, eventually they coauthor papers. It plays a major role in the sustainable development of the cause of science and technology, so universities in our country should strengthen publishing international co-authored papers.

According to statistics supplied by Institute of Scientific and Technical Information of China(ISTIC), the percentage of international co-authored SCI papers published by Chinese researchers gradually increases [2]. China's institutions, which have participated in co-authoring papers, are sorted in five types, such as university, research institution and medical institution. Among them, papers from universities have the highest percentage. In 2010, there are 32,807 international coauthored papers, which account for $22.1 \%$ and are 4333 pieces more than in 2009 , meaning $15.2 \%$ increase. So, more attention should be paid to making full use of foreign advanced scientific research conditions and the easy and fast information channels, fully playing our talent, and developing international cooperation under the condition of complementary advantage and mutual benefit. Then, universities should put all of these into practice [1]. Through cooperation with international universities' professors, 
the overall research level of China's universities can be enhanced.

Third, pay attention to the field of big science studies. "Big science" research is a scientific activity that includes characteristics of huge-investment, interdisciplinary, complexity of laboratory equipment, ambitious goals and so forth. "Big science" project is the comprehensive reflection of the highly developed science and technology, and an important symbol of the world's scientific and technological strength.

That China has already had the capacity to participate in the cooperation on international big science mainly are shown in the following aspects. In recent years, through the participation in International Thermonuclear Experimental Reactor plan, international ocean drilling plan[13, 14], comprehensive global earth observation system and a series of big science plans, China has developed equal cooperation with major technological powers such as the United States, Europe, Japan and Russia, and has made a contribution to setting international standard and resolving important global problems; and the gradually established five international innovation parks, 33 countries and international joint research centers and 222 international technology cooperation base have become crucial platform for China to develop international technology cooperation. With the considerable increase in comprehensive national strength and scientific and technological strength, China has already had the ability to participate in the international big scientific cooperation. Base on the statistics in 2010 [2], the SCI papers covers 20 subjects, but $90 \%$ of these are distributed in high energy physics, nuclear physics, biological sciences, and atmospheric environment and other fields. There are 179 coauthored papers, which involves our country and 22 other cooperating countries. But on the whole, in fields of the big scientific research, the quantity of international publications with the first author of china's scientific researchers is less, and papers involving China's scientific research personnel account for lower proportion. It is imperative to strengthen study of the big science and to enhance the power in this field, so as to promote more high quality papers published. At the same time, it is an important way to strengthen big science projects research for improving our country's scientific and technological strength. Therefore, higher universities should pay more attention to cultivating high-quality talents to participate in the cooperation of international big science.

Finally, strengthen application of the Information network of higher universities. Higher universities should pay more attention to construction of the science and technology information service system, which requires some types of measures [15]. These include constructing network library and journal resources making online journal information abundant, so as to catch up with domestic first-class level; providing Chinese and foreign electronic journals database; expanding the scope; and speeding up of full text paper download and the construction of online forums; and periodically announcing SCI papers situation of each academy. Through these measures, it is useful to enhance function of the Information network of universities, and to make teachers and students get the latest science and technology information. It is also convenient for them to understand the international research hot spot and development direction [16].

In addition, colleges need to attach importance on construction of network system of the scientific research management, by which managers can know scientific research situation timely and find issues of higher universities. It helps deciders to analyze the statistic about 
each teacher's research project, funds, paper published and so forth, to clearly monitor research process, and to urge scientific research personnel to complete research projects well.

\subsection{Propagandize the function of high quality of scientific papers}

Based on the quantity and quality of SCI papers to make evaluation of scientific research is recognized as a basic method in domestic scientific community at present. It is the signature achievements for individuals and universities to publish papers with high quality, which will also have higher influence [10]. Therefore, improving the quality of research papers, and actively writing SCI papers can improve the teacher's accomplishment and research ability, enhance the scientific research competitiveness, and increase the popularity in the scientific community.

Through positively propagandizing the positive influence and function of the quality of scientific papers in higher universities, it is necessary to guide faculty to set up the consciousness of improving the quality of thesis, to make them realize our colleges' backward situation and the more important role of SCI papers in improving universities' competitiveness. To be specific, it is needed to form a sense of anxiety within the whole university and to do propaganda and mobilization work well, in an effort to create a strong cohesion and to arouse the enthusiasm of faculty to publish SCI papers especially for personnel who are engaged in basic application and scientific research.

In addition, universities need actively sum up experience, learn practical methods from other universities, and encourage teachers to have neither the thought of eager for quick success nor hesitation. For teachers, they should positively submit papers to high qualitative journals and promote a further progress on the quality of research papers.
In brief, in order to promote the outputs of SCI papers, higher universities should propagandize the considerable function of scientific and technical papers with high quality, build superior research environment, enhance international cooperation and communication in science and technology, strengthen application of information network system, and deepen reform of the management system for science and technology, so as to promote the development of academic research in higher universities and to enhance the academic level and popularity.

\section{References}

[1] Y. Zhang, Y.C. Fang and Y.Y. Liu, "Probe of Relationships Between the Enhancing of Science Research Level and Cooperation of Science and Technology According to SCI Publications for University", Science \& Technology Progress and Policy, pp.132-134,2005.

[2] Y. H. Wang, "Discussion on reform and innovation of scientific and technological management in higher universities at new stage". Chinese Geological Education, vol.16 no1: 98-101, 2007.

[3] Institute of Scientific and Technical Information of China, Statistical Data of Chinese S\&T Papers in 2011. http://www.istic.ac.cn/.

[4] Z.F. Ma, "Statistical data of scientific and technical papers and the research papers situation", Journalism Lover, pp.70-71,2008.

[5] R. Shi, "Analysis and Thoughts on the SCI Paper Publication of Nanjing University in Recent Years", R\&D Management, vol.21, no.4, pp.115117,2009 .

[6] Z.L. Li, "The Phenomenon Analysis of Paper Nominal Author in a College Topic Research", Journal of 
Modern Information, vol.29, no.1,pp.167-170, 2009.

[7] X.P. Liu and H. Zhou, "Statistical Analysis on the SCI Papers of Peking University in 2005", Acta Scientiarum Naturalium Universitatis Pekinensis, vol.45, no.5, pp.723-727, 2007.

[8] L. Gao, F.Y. Tong and X.A. Deng, "Impact of Sci-tech Basic Inputs on the Output of Papers", Science \& Technology Progress and Policy, vol.24, no.9, pp.25-28, 2007.

[9] Y. Ma, Y. Qin and B.J. Wu, "Impact of Scientific Research Input for Output SCI Paper of Research Type Universities: Case Study of Beijing Jiaotong University", Journal of Beijing Jiaotong University, vol.34, no.6, pp.122-127, 2010.

[10] L.J. Mao, Q.G. Xi, B. Zhang, J.F. Yu and B.Y. Qian, "Statistic Analysis of the Relation between Papers Collected by SCI and Sci-Tech Input and Research Incentive Mechanism in the Nanjing Agricultural University", Journal of Library and Information Sciences in Agriculture, vol.18, no.4, pp.162-164, 2006.

[11] Y.L. Liu and J. Zhao, "What Determines the Quality and Quantity of SCI papers", China Soft Science, no.10, pp.87-94,2003.
[12] Y.J. Dong, S.H. Zhao and L.C. Sun, "From the statistical analysis of SCI paper seeing the development and level of the scientific research in schools", Library Theory and Practice, no.4, pp.52-53, 2005.

[13] L.F. Wang. "Universities should reasonably use the SCI evaluation system", Science and Technology Daily, pp.1-3, 2006.

[14] X.L. Chen and Y.J. Sun, "Collaboration Group Size and It's Impact on the Quality of S.C.C. Ting' s Scientific PerformanceBased on the Analysis of the Relationship between the Number of Co-authors and the Citation Count of His SCI Papers", Journal of Dialectics of Nature, vol.32, no.4, pp.56-63, 2010.

[15] L.Y. Yang, Q.J. Zhou, T. Yue, B.H. Jin. H.L. Ding, "Science's China in 2010: Analysis on Research Level and Disciplinary StructureStatistics and Analysis of SCIindexed Paper", Science Focus, vol.6, no.1, pp.23-50, 2011.

[16] W. Zhao, B.Q. Qu, Y.H. Wang and J. Peng, "Analysis of Scientific Papers of High-level Talents in the Field of Environmental Science in China", Forum on Science and Technology in China, no.12, pp.112-116, 2010. 